\title{
Rastros de utopia: a resistência na pauta do Nicolau (1987-1996)
}

\author{
Scheyla Joanne HORST ${ }^{1}$ \\ Márcio Ronaldo Santos FERNANDES ${ }^{2}$
}

\begin{abstract}
Resumo:
O Nicolau, publicação da Secretaria do Estado da Cultura do Paraná considerada mítica por reunir com entusiasmo a intelectualidade entre 1987 e 1996, se destaca por ter como aspecto marcante a busca pela discussão de assuntos inadiáveis por meio da pluralidade de vozes. A marca defendida em editoriais era de que a essência do jornal mensal estava em promover um registro vivo, inquieto e perturbador daquele tempo. Neste artigo, realizamos uma análise documental e bibliográfica contemplando materiais publicados nos dois primeiros anos do periódico. Selecionamos textos que estão relacionados aos temas Ditadura Militar, Liberdade de Expressão e Censura. Nossas reflexões contemplam discussões a respeito do tipo de Jornalismo praticado pela equipe do Nicolau e ponderações a respeito da pertinência do meio de comunicação para a história cultural do Paraná.
\end{abstract}

Palavras-chave:

Imprensa; Resistência; Ditadura Militar; Cultura.

\section{Utopia traces: resistance on the agenda of Nicolau (1987-1996)}

\begin{abstract}
:
The Nicolau, published by the State Secretariat of Culture of Paraná (Brazil), is considered mythical by gathering with enthusiasm the intelligentsia between 1987 and 1996, and stands out for having as striking aspect of the search for the discussion of urgent issues through the plurality of voices. The vision advocated in editorials was that the essence of the monthly newspaper was to promote a live record, restless and disturbing that time. In this article, we performed a documental and bibliographical analysis covering materials published in the first two years of the journal. Selected texts that related to military government (in the form of dictatorship) issues, freedom of expression and censorship. Our reflections contemplate discussions about the type of Journalism practiced by the Nicolau team and too weightings concerning the relevance of this media vehicle to the Cultural History of Paraná.
\end{abstract}

Keywords:

Press; Resistance; Military dictatorship; Culture.

\section{Rastros de utopía: la presencia de la resistencia en la pauta de Nicolau (1987-1996)}

\section{Resumen:}

Nicolau, periódico de la Secretaría Provincial de Cultura de Paraná (Brasil), es considerada una publicación mítica por reunir, con mucho entusiasmo, la intelectualidad entre 1987 e 1996 y se destaca por tener como aspecto fuerte la búsqueda por la discusión de temas inaplazables por medio de la pluralidad de voces. La visión defendida en editoriales era que la esencia de periódico mensual estaba en promover un registro vivo, inquieto y perturbador de aquel tiempo. En ese artículo, realizamos un análisis documental y bibliográfico contemplando materiales publicados en los dos años iniciales de Nicolau. En la investigación, tenemos textos que están relacionados a temas como Dictadura Militar en Brasil, libertad de expresión y censura. Nuestras reflexiones contemplan discusiones acerca del tipo de Periodismo practicado por el equipo de Nicolau y, además también, ponderaciones respecto a la pertinencia del medio de Comunicación para la Historia Cultural de Paraná.

Palabras clave:

Periodismo; Resistencia; Dictadura Militar; Cultura

\footnotetext{
${ }^{1}$ Jornalista e Mestre em Letras pela Universidade Estadual do Centro-Oeste. E-mail: scheylahorst@hotmail.com

${ }^{2}$ Jornalista e Professor Doutor na Universidade Estadual do Centro-Oeste. E-mail: marciorf@globo.com
} 


\section{INTRODUÇÃO}

Em 2017, a primeira das 60 edições do Nicolau completa três décadas de lançamento. O número 1 do jornal chegou ao público em julho de 1987 como um projeto ousado da Secretaria de Estado da Cultura do Paraná. Já a partir do título, Nicolau, a publicação pretendia representar a diversidade característica do Estado situado no Sul brasileiro e constituído por uma variada corrente imigratória. "E Nicolau, nome familiar aos poloneses, italianos, árabes e alemães, homenageava esta contribuição cultural”, explicou a jornalista Adélia Maria Lopes, completando que um nome próprio também relembraria a trajetória da revista Joaquim, editada na década de 1940 por iniciativa do escritor Dalton Trevisan (LOPES, jul. 1987, p. 3), entre outros.

O encanto até hoje causado pelo Nicolau não se dá apenas pela divulgação de uma pluralidade de ideias e vertentes artísticas que eram elogiadas e incentivadas frequentemente pelos leitores na seção de cartas. Chama a atenção o fato de que, mesmo financiada pelo governo, a publicação conseguiu de certa maneira organizar a indignação e lançar luz sobre temas inadiáveis naquele momento histórico (e que permanecem urgentes até hoje), como: liberdade de expressão e construção da democracia em um país em que ambos os temas estão sempre em risco, como a História mostra. A linha editorial do jornal - ao menos em sua primeira fase, como será explicado a seguir - era pautada, então, pelo olhar insubordinado, que enxergava além do senso comum e problematizava questões que pareciam canônicas naquela sociedade paranaense e brasileira.

É interessante verificar no Nicolau a intenção de apresentar opiniões divergentes e dar voz a quem por muito tempo foi silenciado em outros jornais do País. Pesquisas mostram que no Brasil houve momentos em que a grande mídia, controlada por empresários e grupos poderosos, repetidas vezes agiu em colaboração aos censores. Segundo Claudio Abramo, a Ditadura atuava com dureza, manipulando o que o jornal publicava por meio de negociações com os proprietários dos veículos de comunicação. "Houve um período em que não se podia acreditar em nada que saía impresso; era publicado nos jornais que um guerrilheiro tinha morrido atropelado, quando na verdade tinha morrido numa cela, sob torturas mais bárbaras" (ABRAMO, 1988, p. 120). Ele estava se referindo ao período 1964-1985, iniciado com o Golpe Militar de 1964.

No editorial do número especial a respeito do legado do Nicolau, a equipe do 
Cândido, atual veículo de comunicação impressa da Biblioteca Pública do Paraná, se manifesta: "A audiência conquistada pelo jornal - e sua permanência histórica - não se deve apenas às dificuldades de informação da época, mas principalmente à qualidade do que era publicado" (CÂNDIDO, mar. 2014, p. 2). Tal qualidade apresentava como pressupostos: pontos de vista divergentes, polêmicas, relatos pessoais, artigos advindos de pesquisas, reportagens etc. Tudo isso "temperado" com poesia, prosa, conto, crônica, fotografia, gravura e crítica. As cerca de 30 páginas produzidas a cada mês alternavam entre a ficção e a realidade, entendendo-se que esta última também pode ser construída.

Tomando como inspiração as características que Daniel Piza (2003, p. 111-113) aponta como fundamentais para que o já extinto caderno Fim de Semana, da Gazeta Mercantil (jornal que deixou de circular em 2009), ainda exerça influência em profissionais e seja lembrado quando se fala em Jornalismo Cultural, percebemos a ocorrência dos mesmos itens na história do Nicolau. As cinco hipóteses para a perenidade do veículo informativo, conforme Piza (2003), podem ser essas: a periodicidade (mensal); o público qualificado (ampla participação na seção de cartas); a combinação de gêneros e temas (variedade de expressões); a equipe (engajada e qualificada) e, por fim, mas com grande destaque, a "carta branca", que é a liberdade editorial.

Para José Castello (2010, p. 26-29), só é possível realizar bom Jornalismo Cultural com base em "princípios inconstantes", isto é, sem dogmas e regras, mas com multiplicidade de caminhos que são trilhados pela equipe. Ele cita algumas inconstâncias que se destacam também em Nicolau, em nosso ponto de vista: pluralismo, que é a diversidade e a fragmentação; coração desarmado, que representa a abertura de espaço para divergências; impulso de transformação, quando se aceita e se segue o movimento constante da cultura; liberdade interior, manifestada pela contaminação com o mundo, e coragem para lidar com algo que é caótico e contraditório. "O repórter deve partir não de si, mas do outro. Deixar-se penetrar pelo impacto que o outro sempre provoca. A cultura é o campo do outro: o da surpresa, do desconhecido. Expor-se - não existe bom jornalismo sem alguma dose de risco e de contaminação" (CASTELLO, 2010, p. 28).

Podemos fazer uma relação do que encontramos na equipe do Nicolau também com os cinco atributos de uma profissão no ponto de vista de Greenwood, as quais são citadas por Nelson Traquina (2004), na obra Teorias do Jornalismo. Os fatores são os 
seguintes: teoria sistemática (experiência tanto intelectual quanto prática); o sentimento de autoridade por parte dos agentes especializados (o profissional escolhe o que é bom ou mal para o cliente); a ratificação de uma comunidade (a autoridade profissional proporciona poderes e privilégios); códigos éticos (existem reguladores formais e informais que são seguidos pelos profissionais) e a existência de uma cultura profissional (valores, normas e símbolos compartilhados pelos pares). Com base em tais características, podemos perceber que existia um trabalho profissionalizado em Nicolau e que buscava atingir resultados e causar impacto, mesmo sem ser um jornal de notícias convencional.

Este artigo objetiva, por meio de análise interpretativa documental e bibliográfica, evidenciar o papel desempenhado pelo Nicolau no final da década de 1980 e início dos anos 1990 no que se refere à discussão de assuntos relacionados à Ditadura Militar e suas consequências para o Paraná. A partir de um posicionamento qualitativo, pretendemos refletir e apontar características do tipo de Jornalismo produzido pela publicação, bem como apresentar a sua importância para a memória cultural do Estado. A equipe Nicolau era composta por escritores, jornalistas, ilustradores e fotógrafos e recebia colaborações constantes de poetas e pesquisadores de diversas áreas do conhecimento, além de comentários de profissionais. Wilson Bueno, o editor-chefe, era escritor e procurava proporcionar aos participantes do projeto espaço para experimentações. Também tentava compartilhar com o público vozes pelas quais nutria admiração (SANTOS, 2014, p. 32).

\section{Chapa multicolorida}

Em relato no qual rememora sua participação como freelancer na equipe do Nicolau, o poeta e jornalista Rodrigo Garcia Lopes afirma que o ambiente de trabalho era bastante inspirador, transmitindo aos participantes do projeto uma aura de descontração e liberdade. Todas as etapas da criação, segundo ele, eram democráticas, com discussão conjunta dos temas e pautas e colaboração de todos os envolvidos na busca por contatos e definição do enfoque. Por um bom tempo, houve uma seção fixa de editorias, como Mosaico, Tradução, Depoimentos, Fotografia, Ensaio, Dossiê. Tais títulos organizavam o processo e garantiam uma variedade de produções a cada edição publicada mensalmente. As impressões eram celebradas. "A gente sabia que cada número era uma vitória, ainda mais dentro de uma estrutura oficial, estatal. Resumindo, 
foi um período turbulento, mas muito gostoso e criativo. Por isso, considero cada número daquela época como único" (LOPES, mar. 2014, p. 26), ressalta o profissional, lembrando que nem tudo foram flores na história do periódico:

Creio que o fato da equipe defender, com unhas e dentes, a autonomia e ousadia do jornal, recusando-se a fazer jornalismo "chapa branca", também foi incomodando o poder. Éramos independentes, ambiciosos, criativos demais. O Bueno e equipe sofriam muita pressão. Política, institucional, ideológica. (LOPES, mar. 2014, p. 27).

Tal preocupação existia desde o início do trabalho, conforme o próprio editor, o escritor Wilson Bueno, deixava claro sempre que necessário em inserções no editorial. O número 6 é um bom exemplo: "Jamais, em nenhum momento, até aqui, da trajetória do Nicolau, sofremos qualquer tipo de pressão, procedente de qualquer instância ou escalão do Governo" (BUENO, dez. 1987, n. 6, p. 2). É interessante frisar o adendo até aqui usado por ele, destacando a característica de instabilidade que pairava no ar. Ele completou: "Em caso contrário, nos recusaríamos a subescrever a publicação que se quer um espaço aberto e democrático, única forma capaz de refletir o hoje e o agora da criatividade de nossa gente". Em seu ponto de vista, não seria capaz consignar a verdade, pois o risco de acabar no círculo vicioso e viciado da omissão - ou ainda no jornalismo chapa-branca, que é o nome atribuído à prática que procura manter privilégios de poucos sobre muitos e, assim, se distancia do interesse público.

Logo na edição que inaugurou o jornal, Bueno expôs que o Nicolau nascia com a missão de reunir variantes do pensamento, num esforço coletivo e contínuo para o desenvolvimento humano através da construção coletiva de um País democrático. "Isto, numa publicação oficial, sob os auspícios do Estado, dá bem a medida do esforço em que todos estamos empenhados pela construção da Democracia brasileira" (BUENO, jul. 1987, n. 1, p. 2). O secretário da Cultura que incentivou o nascimento do jornal foi René Dotti, dentro da equipe liderada pelo então governador Álvaro Dias.

Na dissertação intitulada O Nicolau, um jornal cultural, defendida há mais de 15 anos, a pesquisadora Maria Lúcia Vieira considera que a publicação nasceu dentro de uma administração pública que se pretendia inovadora e preocupada em se mostrar diferente para a população num período histórico que demandava esse tipo de posicionamento. Todavia, não persistiu, existindo como um movimento cravado num período específico, sendo difícil encontrar propostas semelhantes e com grande visibilidade nos dias de hoje. "A iniciativa cultural do Nicolau, mesmo que tenha 
movimentado todo tipo de classe, se manifesta como isolada de uma gestão idealista, menos preocupada com sua continuidade e mais com a sua expressividade" (VIEIRA, 1999, p. 987).

No ponto de vista quiçá extremado de Rodrigo Garcia Lopes, o Nicolau foi a tradução da sua época, "pré-internet e barbárie cultural, de fala alijada, perda de referências e materialismo desenfreados, quando as pessoas eram movidas por alguma utopia ou princípio-esperança" (2014, p. 27). Tal posicionamento se harmoniza com o que já afirmou ironicamente a jornalista Adélia Maria Lopes em entrevista, sobre o fim daquela geração de confrontadores: "Tudo foi desaparecendo: a Casa do Poeta, a boemia, as pessoas, Leminski, Alberto Cardoso, Poty, Paquito Modesto, Helena Kolody, a inquietação, a massa crítica. Com os acadêmicos, a explicação. Ou com Freud?" (TEIXEIRA, 2007, p. 38). Ambos os depoimentos de integrantes da equipe ressaltam o momento e os personagens envolvidos como fundamentais para o estabelecimento e circulação do Nicolau, que não apenas alcançou o Paraná, mas também outros Estados e até países, por meio de divulgação gratuita.

\section{Um olhar aos textos}

A temática relacionada à resistência permeou diversos gêneros textuais no meio de comunicação, que também era bastante diverso. Por isso, realizamos uma sondagem mais profunda nas edições que compõem a primeira fase do Nicolau (1987-1989), quando estava mais evidente o comprometimento da equipe com o projeto inicial, tendo em vista que, por estar inserida no âmbito governamental, a publicação foi afetada por trocas de administrações. Dessa maneira, coletamos os textos que fazem menção ao assunto, sendo que ressaltaremos alguns deles aqui para discussão e aprofundamento. A equipe que inaugurou o Nicolau foi desmobilizada, conforme pesquisadores, por uma série de motivos. Desde a instalação de um conselho editorial na altura do número 26 que cercearia a liberdade, na opinião de alguns membros do grupo - até mudanças mais contundentes, como troca de governadores e secretários após eleições, com consequentes tentativas de alterar a dinâmica do meio de comunicação.

Com base em Jacques Sémelin (1994), percebemos que só existe resistência quando ela é coletiva, isto é, compartilhada por um grupo de pessoas. A linha editorial inaugural do jornal procura se formar dessa maneira. Considerando que resistir também pode ser reagir, podemos transpor tal ideia para a postura do coletivo de pessoas 
envolvidas no projeto. Se historicamente os grupos resistentes surgem da base e não da ação do Estado, o fenômeno instalado em Nicolau chama a atenção. Como resistir é atacar, isto pode se desenvolver de diferentes maneiras, como por exemplo, a partir da inquietude e da publicação daquilo que até então não ganhara visibilidade.

No meio do percurso, como já afirmamos, houve uma ruptura do grupo, à altura da edição número 26. "Na ocasião, a pequena equipe se demitiu unanimemente do projeto, em solidariedade com o designer e produtor gráfico Luiz Antonio Guinski, na esteira da sua arbitrária demissão, provocada por divergências com o secretário da Cultura na época" (BRAND, 2014, não paginado), escreveu o jornalista e doutor em História Jaques Mario Brand, num artigo de opinião publicado na Gazeta do Povo. Sobre a ruptura, Brand acrescenta:

Desse momento em diante, vive outra fase, outra estética, com outra redação e outra dinâmica - embora mantivesse, no essencial, as seções e colunas desenvolvidas na fase heroica, inaugural. Sob o prisma de sua organização interna, o mais notável dos fatores que marcaram a primeira fase, gradualmente revogado à medida que a publicação se firmava como referência, foi o caráter coletivo do trabalho editorial. (BRAND, 2014, não paginado).

Se a história do Nicolau fosse dividida em a.C (antes da crise) e d.C (depois da crise), a primeira fase possivelmente seria intitulada heroica, como, aliás, foi chamada por membros do grupo, como Rodrigo Garcia Lopes. O jornal ocupa relevante espaço na história da imprensa paranaense. Durante sua história, recebeu, entre outros, o prêmio de Melhor Veículo de Divulgação de Cultura de 1987 da Associação Paulista dos Críticos de Arte e de Melhor Publicação Cultural na América Latina em 1991, no Encontro Nacional de Escritores que ocorreu em Brasília. É importante ainda considerar que o jornal foi encartado como suplemento de cultura em pelo menos 25 meios de comunicação diários ao redor do Estado, disseminando as informações por todo o território paranaense com amplitude, contemplando o interior e chegando a ter tiragem de 160 mil exemplares. O poeta Rodrigo Garcia Lopes - que integrou a equipe em ambos os períodos - relata no texto Com quantos paus se fazia um Nicolau detalhes a respeito da demissão em massa:

A crise estourou no número 26, quando a equipe foi forçada pelo secretário da Cultura (e pelo Wilson Bueno) a engolir um conselho editorial. Nós fomos contra, pois conhecíamos os interesses que haviam por trás da decisão e sabíamos que aquilo seria o início do fimm de um projeto que nasceu coletivo. Na esteira da arbitrária demissão de Guinski, quase toda a equipe saiu, inclusive eu, em solidariedade. 
(LOPES, mar. 2014, p. 27).

Da primeira baixa da equipe original até a última - cinco edições antes do fim do Nicolau, com a saída do próprio editor, Wilson Bueno - a proposta foi perdendo um tanto de sua rebeldia e se enquadrando mais na ideia típica de suplemento literário, com destaque sobretudo para poesia, prosa e resenhas. Nosso foco, então, neste trabalho, se concentra nos dois anos iniciais do jornal. Realizamos a leitura minuciosa dos documentos e selecionamos materiais de diferentes gêneros textuais jornalísticos: editoriais, notas opinativas, artigos, ensaios pessoais e reportagens. $\mathrm{O}$ acesso às fontes foi facilitado porque em 2014 a Secretaria de Estado da Cultura publicou uma edição fac-similar do jornal. A reedição contempla os 60 números do suplemento, lançada após mais de dois anos de trabalho da equipe da Biblioteca Pública do Paraná (BPP), também disponíveis no site da instituição. Os originais podem ser consultados na sede da biblioteca, em Curitiba (PR).

Os famosos 20 anos, como são chamadas as duas décadas de ditadura entre março de 1964 e abril de 1984, quando foi libertado o último preso político do País, foram tema de várias inserções divulgadas no Nicolau. A edição de número 18, por exemplo, publica uma resenha e um trecho do livro Resistência Democrática - A Repressão no Paraná, organizado por Milton Ivan Heller. No texto , o jornalista Nilson Monteiro se posiciona a respeito da pertinência da obra, que ele considerou bastante oportuna para aquele período de transição. "Só no Paraná, houve 2.726 prisões por motivos políticos, de março de 64 a março de 79. E o livro vem acordar esse tempo, onde a truculência e o desrespeito viraram praga, mas também a solidariedade se espalhou, viva, dentro e fora das prisões” (MONTEIRO, dez. 1988, n. 18, p. 26).

Ao lado da resenha de Monteiro, o Nicolau apresenta um texto assinado por Heller, com o título Prendiam gente boa, no qual conta alguns fragmentos que são discutidos no livro. Ele é enfático ao apresentar constatações da sua pesquisa, trazida ao público apenas quatro anos após o estabelecimento da Nova República: "Toda Ditadura tem ódio mortal à inteligência. Tem medo das pessoas esclarecidas e conscientes", afirmou o autor, que também era jornalista, completando: "Em nosso Estado, a universidade ainda não se recuperou das baixas da repressão. Principalmente porque ela deixou de ser uma universidade pluralista, resultando neste tipo de instituição que temos hoje: anestesiada" (HELLER, dez. 1988, n. 18, p. 27).

Constatamos na edição 18 um espaço interessante ao tema (duas páginas 
completas) e também a citação do assunto no espaço destinado ao editorial, isto é, onde o editor fala a respeito da construção do número. Como mostra o trecho a seguir, de maneira poética, como era característica de Bueno, ele ressalta a importância de olhar para trás para a construção do futuro. Duas palavras usadas por ele mostram a necessidade de dar o nome mais próximo dos acontecimentos: tirania e tortura. Não há meias palavras ou amenizações, o que ele deixa claro na expressão "dossiê sinistro da repressão entre nós".

Re-olhamos lá atrás: foi duro e mártir a resistência à mais recente tirania brasileira e contamos, entre perdas e danos, o saldo bem trágico de nossa queda-de-braço com o futuro. Pela primeira vez, o Estado patrocina o dossiê sinistro da repressão entre nós, através do livro de Miton Ivan Heller (Resistência Democrática - A repressão no Paraná), objeto de ampla matéria nesta edição - da visão particular e pessoalíssima de Nilson Monteiro ao depoimento das vítimas no país da delação e da tortura. (BUENO, dez. 1988, n. 18, p. 2).

Uma reportagem publicada no número 9, em março de 1988 - ano em que a Constituição Federal denominada cidadã seria promulgada - é marcante nesta ideia que apresentamos até aqui. A jornalista Adélia Maria Lopes - que fazia frequentemente matérias para o periódico - assina o texto A Louca do túnel de março do meu país, em que narra as vivências de Julybia Jupyra Barreto de Faria, uma mãe moradora de Curitiba que teve seus quatro filhos presos pelos militares por questões políticas. $\mathrm{O}$ relato compôs também o recém-citado livro de Heller (Resistência Democrática), mas foi publicado em Nicolau antes disso, em duas páginas ilustradas com uma foto da personagem, um retrato da família completa e poesias escritas por um dos rebentos de Julybia.

Já o título da reportagem é um verso de uma poesia de Hamilton Faria, que faz referência ao mês em que o Golpe Militar foi deflagrado no país e aos subterrâneos que aquela mulher teve de conhecer para localizar e visitar seus filhos. Como tantas outras mães, ela foi aos extremos para acompanhar os processos, como fica claro no trecho: "Quando sequestraram o embaixador suíço, os presos da Ilha das Cobras ficaram sem receber visitas. Menos o Hamilton. Dona Julybia tirou os sapatos, ficou descalça andando sobre as pedras até sensibilizar os carcereiros." (LOPES, mar. 1988, n. 9, p. 11). Veja como a repórter inicia a matéria, construindo uma cena que apresenta a entrevistada e também resume o que será discutido nos parágrafos a seguir. É mostrado o perfil de uma mulher guerreira: 
O mês de março de 1964 encontrou dona Julybia Jupyra Barreto de Faria atarefada com os quatro filhos da casa, todos com garbo, trajando o uniforme do Colégio Militar do Paraná. Outros marços encontraram esta mesma senhora perambulando por quartéis em busca dos seus quatro filhos. "Penso que sou a única mãe brasileira que matriculou quatro filhos no Colégio Militar e que teve todos eles presos pelos militares. Comigo é tudo exagerado". E neste março de 88 , na mesma casa de madeira rodeada de abacateiros e goiabeiras, em plena área central de Curitiba, e onde derramou seu pranto e dali partiu decidida a lutar pela liberdade dos filhos, esta mãe rememora aqueles tempos. Nascida na cidade de Laguna há 69 anos, antes de mais nada ela compara: "Já lutei mais que Anita Garibaldi". (LOPES, mar. 1988, n. 9, p. 10).

O texto causou repercussão e uma carta de leitor sobre a produção foi publicada na edição seguinte. Assinada pelo padre Zeferino Ranzolin, do município de Capitão Leônidas Marques (PR), o breve depoimento parabeniza a edição e a iniciativa do Nicolau que contempla a reportagem e incentiva a equipe a permanecer naquele caminho. No decorrer da carta, o leitor afirma: "Realmente, jamais será louca a mãe que tudo sacrificou pelos 'meninos'. Dona Julybia, além de mãe, travou uma luta em prol dos Direitos Humanos. Portanto, valor de mãe e de honra" (RANZOLIN, mar. 1988, n. 10, p. 26).

Na sexta edição do Nicolau, em reportagem, ao falar a respeito da série de textos que foram cortados pelos censuradores do jornal alternativo Movimento, o escritor João Antonio tece uma reflexão a respeito da relevância da imprensa nanica no País durante a Ditadura Militar, bem como aponta características do povo brasileiro quanto ao esquecimento das consequências do cerceamento à liberdade de expressão.

Sem dúvida, sustenta-se no momento brasileiro uma tendência para se esquecer rapidamente o papel e estragos da censura nos últimos vinte anos, em particular na década de setenta, quando as coisas ferveram em matéria de teatro, música popular, ciência, Igreja e Estado, livro, Imprensa em geral e Imprensa nanica em particular. (ANTONIO, dez. 1987, n. 6, p. 10).

Duas páginas foram destinadas ao material, que contempla um texto denso e opinativo, escrito na forma de ensaio. Com a grande mídia colaborando com os censores, sobrava aos pequenos e alternativos jornais o papel de escancarar o outro lado. E é tal abordagem que João Antonio realiza.

Luiz Manfredini assina um texto exclusivo para o $11^{\circ}$ Nicolau sobre a tomada da Reitoria da Universidade Federal do Paraná por estudantes em 14 de maio de 1968. Por meio de ensaio pessoal, o jornalista descreve como foi o processo de ocupação 
impulsionado pelo início de cobrança de anuidade, o que os alertava para a possibilidade de encerramento da gratuidade da instituição de ensino superior. "No Brasil, os estudantes iam à forra com o regime militar instalado quatro anos antes. No Rio de janeiro, a 24 de março, o secundarista Edson Luiz de Lima Souto fora assassinado pela polícia. Havia um clima de sedição juvenil” (MANFREDINI, maio 1988, n. 11, p. 5). Contra os policiais armados, os milhares de alunos se protegiam munidos com bolas de gude, rolhas de cortiça, estilingues e rojões.

$\mathrm{Na}$ inserção da edição 11, é evidente o tom memorialístico, como se fosse preciso ressaltar constantemente que é necessário lembrar o que aconteceu duas décadas antes, para que não se repita. $\mathrm{Na}$ apresentação da matéria, o editor de Nicolau afirma que o simbólico ato de rebeldia dos estudantes paranaenses naquela ocasião lembrava a batalha bíblica entre Davi e Golias. Ou seja: um jovem contra um gigante, numa luta desigual. Bueno considera, no editorial do exemplar, que o texto de Manfredini congrega "flashes de digna indignação contra a nossa mais recente ditatura" (BUENO, maio 1988, n. 11, p. 2).

No espaço destinado ao editorial, que é aquele tipo de produção que divulga o posicionamento do meio de comunicação em texto geralmente assinado pelo editorchefe, Wilson Bueno se manifestava frequentemente sobre os temas aqui discutidos (ditadura, resistência, utopia, liberdade de expressão). Visivelmente, o jornalista e escritor se esforçava para expressar os pontos preponderantes da linha editorial trilhada por Nicolau. Ele também procurava dar um feedback aos leitores a respeito das participações materializadas em opiniões dirigidas à redação. Acompanhe o manifesto de Bueno inserido na edição $n^{\circ}$ 4:

\begin{abstract}
A trajetória do Nicolau, até aqui, já nos permite dizer, sem erro, que somos muitos. Mais do que a nossa primeira intuição deduziu, mais do que supôs a nossa (vã) expectativa. A julgar pelas cartas, telegramas, telefonemas ou pelos numerosos textos espontaneamente chegados à redação, podemos afirmar que somos muitos - nos bairros, nas cidades, nos Estados, no País. E é, sobretudo, esta solidariedade de raiz que funda, alimenta e constrói os nossos melhores propósitos. Considerado, por gente rigorosa, como saudável inventiva na história das publicações culturais do Brasil, Nicolau continua aferrado à ideia de que só a pluralidade de pensamento será capaz de refletir, por inteiro, a nossa singularidade. E nem poderia ser de outra forma, se estamos sinceramente empenhados na construção da democracia brasileira. (BUENO, out. 1987, n. 4, p.2).
\end{abstract}

"Sinceramente empenhados na construção da Democracia brasileira". É assim 
que o editor define o sentimento compartilhado pela equipe. Pensamos que este ponto de vista não dizia respeito apenas ao combate à Ditadura e à consolidação da Constituinte, mas também à necessidade de tirar da censura e do porão a cultura praticada fora da capital do Estado. De acordo com o que recorda Rodrigo Garcia Lopes, em relato ao jornal Cândido, uma das preocupações do Nicolau era "descuritibanizar" o periódico, relevando o que estava sendo feito em outras partes do Paraná com igual peso e valor. "Isso acabou descentralizando e mostrando que havia vida inteligente no Estado" (LOPES, mar. 2014, p. 26). A prova de tal ponderação pode ser percebida na pauta dedicada às reportagens, pois os textos contemplaram assuntos de diversas cidades, atingindo a maioria das regiões, como Litoral, Região Metropolitana, Campos Gerais, Norte e Centro-Oeste do Paraná.

\section{Considerações possíveis}

Como observamos nos textos selecionados para este artigo, o jornal se preocupava em discutir e apresentar relatos e números sobre a Ditadura Militar após o seu final. Acreditamos que tal posicionamento se caracterizava como uma busca para trazer à tona relatos até então não ouvidos e mostrar os lados que a grande mídia de certa forma ignorou durante e até mesmo após o fim da censura, por focar nos dados oficiais ou receber orientações/direcionamentos dos militares. Logo na terceira edição, uma nota inserida em Nicolau relembra: "Mais de 5 mil cidadãos tiveram mandatos cassados e seus direitos políticos suspensos; 12 mil processados pelas auditorias militares e 10 mil foram obrigados ao exílio" (LINCK, 1987, n. 2, p. 3). Nesse contexto, verificamos que havia um engajamento com a luta pela redemocratização ao mesmo tempo em que o medo do retorno da Ditadura pairava no ar e necessitava ser combatido. Por isso, existe uma postura ligada à resistência na pauta do jornal.

Apesar de suas características - ser um jornal de cunho cultural viabilizado pelo Governo do Estado do Paraná - verificamos que o Nicolau promovia Jornalismo com atitude diferenciada. Em Conceitos de Jornalismo, o autor Michael Kunczik apresenta uma visão do Jornalismo que se engaja e, por isso, se destaca pela ética e pela responsabilidade. Trata-se do Jornalismo de Desenvolvimento, que consideramos ser o mote da pauta no Nicolau. Para Kunczik (2002, p. 346), "a tarefa do Jornalismo de desenvolvimento é oferecer uma mão orientadora para aumentar as possibilidades de participação no mundo; em uma palavra: dar sentido às coisas". 
Dessa maneira, na opinião do pesquisador, é complicado considerar que os meios de comunicação mais tradicionais, com intensos interesses comerciais e de propriedade privada, que mantêm foco na competição com empresas concorrentes, sejam os mais adequados para promover um Jornalismo de Desenvolvimento, pois: "Enquanto o Jornalismo praticado pelos meios comerciais gira primordialmente em torno da demanda, o Jornalismo de Desenvolvimento se concentra sobretudo na oferta" (KUNCZIK, 2002, p. 365).

Segundo Kunczik, ainda, tal tipo de Jornalismo não pode ser utilizado para dar legitimidade a estruturas de Governo que são injustas e os profissionais que o realizam necessitam de uma visão aguçada e específica da História, com capacidade de elaborar críticas fundamentadas. Dessa forma, para o autor, o jornalista de Desenvolvimento "precisa estar convencido de que o futuro da humanidade não está determinado unicamente pelo seu passado. O futuro deve ser visto como algo capaz de ser moldado ativamente" (KUNCZIK, 2002, p. 351). Tal ideal era ressaltado repetidamente pelo Nicolau, como fica evidente na apresentação do projeto no lançamento do jornal: "Temos um único e inextricável compromisso: o de contribuir, ainda que modestamente, para o progresso humano, sem o que a vida de um homem não faz sentido, nem o seu destino" (BUENO, jul. 1987, ano 1, n. 1, p. 2).

Seguindo esta linha de pensamento, acreditamos, com base na ideia de Elaine Tavares (IHU Online, 2012, não paginado), autora do livro Em Busca da Utopia: os caminhos da reportagem no Brasil, dos anos 50 aos anos 90, que o Nicolau carregava em sua essência rastros da boa utopia, que equivale a um Jornalismo praticado como forma de conhecimento, ultrapassando fronteiras de manipulação à direita ou à esquerda. A utopia pulsava nas ideias e posicionamentos dos envolvidos no projeto, desde a primeira até a última página. Ela se expressava, em nosso ponto de vista, na criatividade, nas polêmicas e nos temas abordados. A utopia estava ali desde o primeiro número, quando, em editorial, Wilson Bueno procurou explicar a linha editorial do periódico: "Nicolau se insere no espaço de um novo tempo nacional em que a pluralidade de ideias é um dado inquestionável e tão mais enriquecedora quanto maiores forem as oportunidades de que se promova a sua livre circulação" (BUENO, jul. 1987, ano 1, n. 1, p. 2).

Dessa forma, finalizamos este artigo com a ideia de que, mesmo sem o caráter noticioso ser o foco de Nicolau, o jornal da Secretaria de Estado da Cultura do Paraná 
contribuiu pontualmente para a discussão de temas pertinentes para aquele momento histórico, agindo em prol do desenvolvimento do Paraná e do Brasil. Como a sua tiragem era expressiva (média de 100 mil exemplares por edição) e a distribuição gratuita era também focada em locais de grande circulação de pessoas, o seu impacto atingia vários municípios brasileiros. Ao mesmo tempo, o veículo de comunicação colaborou para que a memória em relação a alguns acontecimentos ocorridos entre 1964-1984 viessem à tona nas páginas dos exemplares, dando visibilidade e espaço a opiniões divergentes daquelas oficiais que eram bastante repetidas durante a censura no país.

O Nicolau reverberou em outros Estados e países, ultrapassando as fronteiras do Paraná e suas 399 cidades. Somente a edição $n^{0}$ 11, usada aqui como um exemplo, mas que apresenta situação semelhante à das outras edições observadas para este artigo, encontramos opiniões de pessoas de Curitiba (PR), Londrina (PR), Ribeirão Preto (SP), Rio de Janeiro (RJ), Niterói (RJ), Santo Antonio da Platina (PR), São Paulo (SP), Vitória (ES), Manágua (Nicarágua), Natal (RN), Medianeira (PR), Salvador (BA), Porto Alegre (RS), Santo Antonio de Jesus (BA), Praia de Leste (PR), Araraquara (SP), Rio Branco (AC), Fortaleza (CE), Cascavel (PR) e Francisco Beltrão (PR).

Por fim, consideramos que o Nicolau (em sua primeira fase) serve como um exemplo positivo de publicação financiada com dinheiro público que não procura ser panfleto da administração, mas que, ao contrário, busca a pluralidade de vozes e temas e a amplitude de questões prioritárias, como democracia e progresso humano. Por tudo isso, não é um projeto comum de ser encontrado nos dias de hoje. Na escrita da história da publicação, como afirmou Wilson Bueno (1987, jul.p. 2) em um dos editoriais, o grupo de colaboradores manteve como profissão de fé e marca a tentativa de um Jornalismo "vivo, inquieto e perturbador" para o registro do tempo em que existiu. Aspectos que deviam ser identificados em todo tipo de Jornalismo, afinal.

\section{Referências}

ABRAMO, Claudio. A regra do jogo: o jornalismo e a ética do marceneiro. São Paulo, Companhia das Letras, 1988.

ANTÔNIO, João. Escapada: Considerações em torno à censura imposta a um jornal alternativo, Movimento, nos anos 1975-1981. Nicolau, Curitiba, ano 1, n. 6, p. 10-11, dez. 1987.

BRAND, Jaques Mario. Nicolau, uma nova narrativa. Gazeta do Povo, Curitiba, 
Caderno G, não paginado. 08 maio 2014. Disponível em:

$<$ http://www.gazetadopovo.com.br/cadernog/conteudo.phtml?id=1467160 $>$. Acesso em: 06 jul. 2016.

BUENO, Wilson. Editorial. Nicolau, Curitiba, ano 1, n. 1, p. 2, jul. 1987.

. Editorial. Nicolau, Curitiba, ano 1, n. 4, p. 2, out. 1987.

Editorial. Nicolau. Curitiba, ano 3, n. 27, p. 2, set./out./nov. 1989.

. Editorial. Nicolau, Curitiba, ano 1, n. 11, p. 2, maio 1988.

CÂNDIDO. Editorial. Cândido, Curitiba, n. 34, p. 2, maio 2014.

CASTELlO, José. Movimento do Desassossego. In: Rumos Itaú Cultural. Princípios Inconstantes. São Paulo, 2010, p. 26-29.

HELLER, Milton Ivan. Prendiam gente boa. Nicolau, Curitiba, ano 2, n. 18, p. 27, maio 2014.

IHU On-Line. O jornalismo pode ser transformador, pode embalar a utopia. Entrevista especial com Elaine Tavares. Instituto Humanitas Unisinos, 25 abr. 2012. Disponível $\mathrm{em}:<\mathrm{http}: / / \mathrm{www}$.ihu.unisinos.br/entrevistas/508771-o-jornalismo-pode-ser-

transformador-pode-embalar-a-utopia-entrevista-especial-com-elaine-tavares $>$. Acesso em: 6 jul. 2016.

KUNCZIK, Michael. Conceitos de Jornalismo: Norte e Sul: manual de Comunicação. São Paulo: Edusp, 2002.

LINCK, Rodolpho. Resistência democrática. Nicolau. Curitiba, ano 1, n. 2, Painel, p. 3, ago. 1987.

LOPES, Adélia Maria Lopes. A louca do túnel de março do meu país. Nicolau, Curitiba, ano 1, n. 9, p.10-11, mar. 1988,.

. A opção Nicolau. Nicolau, Curitiba, ano 1, n. 1, p. 3, jul. 1987.

LOPES, Rodrigo Garcia. Com quantos paus se fazia um Nicolau. Cândido, Curitiba, n. 34, p. 26-27, mar. 2014.

MANFREDINI, Luiz. Nós, de estilingue, atrás das barricadas. Nicolau, Curitiba, ano 1, n. 11, p. 5, maio 1988.

MONTEIRO, Nilson. Nanicos, rebeldes, combatentes. Nicolau, Curitiba, ano 2, n. 14, p. 20-23, ago. 1988 .

Resistência Democrática. Nicolau, Curitiba, ano 2, n. 18, dez. 1988.

PIZA, Daniel. Jornalismo Cultural. São Paulo: Contexto, 2003. 
RANZOLIN, Zeferino P. Cartas na Página. Nicolau. Curitiba, ano 1, n. 10, p. 26, abr. 1988.

SANTOS, Marcio Renato dos. O jornal também faz parte do legado do escritor. Cândido, Curitiba, n. 34, p. 32-33, maio 2014.

SÉMELIN, Jacques. Qu'est-ce que 'résistir'?. Paris: Esprits, 1994.

TEIXEIRA, Selma Suely. Jornalismo cultural: um resgate. Curitiba: Gramofone, 2007.

TRAQUINA, Nelson. Teorias do jornalismo: porque as notícias são como são. Florianópolis: Insular, 2004.

VIEIRA, Maria Lúcia. O Nicolau, um jornal cultural. 1999. 215 f. Dissertação (Curso de Pós-Graduação em Letras) - Universidade Federal do Paraná, Curitiba, 1999. 